\title{
Modeling and research of temperature distribution in surface layer of titanium alloy workpiece during AEDG and conventional grinding
}

Received: 5 October 2015 / Accepted: 14 May 2016 / Published online: 4 June 2016

(C) The Author(s) 2016. This article is published with open access at Springerlink.com \begin{abstract}
to:
- estimation of the frictional heat generating based on friction forces distribution,

- spatial, not only planar, shape of the contact area,

- generated heat partition between different parties of the grinding process,

- heat transfer in the multilayered environment.
\end{abstract}

Abstract Titanium and its alloys are widely recognized as the hardly machinable materials, especially due to their relatively high hardness, low thermal conductivity and possible subcritical superplasticity. Then, a thorough control of the machining process parameters shall be maintained. In this paper, we have concentrated on the grinding of the Ti6 Al4V titanium alloy using cBN (boron nitride) grinding wheel combined with the AEDG (abrasive electrodischarge grinding) process. The mathematical model we have dealt with has been based mainly on Jaeger model of the heat taking over between sliding bodies with substantial upgrades related

The experimental verification of the theoretical predictions has been carried out. Fundamental difficulty in such a research is placing temperature probes sufficiently close to the ground surface with possibly low space devoted for probes due to the temperature field deformation with relation to the real conditions of grinding. The temperature field in the machined workpiece has been investigated using electronic data logging and DSP methods. Obtained results exhibit clearly that distribution of heat generation in the contact zone could be of the relatively complicated shape due to the external cooling and the very specific heat transfer and accumulation in the titanium workpiece surface layer.

Keywords AEDG grinding $\cdot$ Grinding temperature $\cdot$ Titanium alloy $\cdot$ Heat transfer $\cdot$ Jaeger model

Communicated by Andreas Öchsner.

M. Gołączak (凶)

Institute of Machine Tools and Production Engineering, Lodz University of Technology, 90-924 Lodz, Poland

E-mail: marcin.golabczak@p.lodz.pl

A. Gołąbczak · A. Konstantynowicz · R. Świecik

Department of Production Engineering, Lodz University of Technology, 90-924 Lodz, Poland

E-mail: andrzej.golabczak@p.lodz.pl

A. Konstantynowicz

E-mail: andrzej.konst@gmail.com

R. Święcik

E-mail: robert.swiecik@p.lodz.pl 


\section{Preface}

Temperature in the grinding abrasion zone proves to be one of the most important factors influencing the quality of the machined workpieces. Excessive temperature causes deterioration of the shape and dimensional precision as well as the unfavorable changes in the surface layer state and features of the machined wares. The most disadvantageous changes in the surface layer are, among others, grinding burns, structural changes of material (eq. requenching, recrystallization), and increase in the internal stresses $[4,7,8]$. Temperature during the conventional grinding depends mainly on grinding parameters, such as depth of grinding, feed, perimeter speed of the grinding wheel, and the grinding wheel active surface state. During the AEDG process, aside of the mentioned factors, additional heat energy of the spark discharges has to be taken into account which distinctive value could be estimated through the electrical parameters of the impulse generator.

Recognition of the exact temperature in the contact zone between machined material and grinding wheel, especially in the surface layer, has the essential significance during design process of the grinding technological operations of the hardly machinable construction materials. In this paper, some results have been presented related to mathematical modeling and experimental researches of the temperature distribution in the surface layer during the conventional and electroerosive grinding of the titanium alloy Ti6A14V with using cooling dielectric liquid. In the mathematical modeling, some version of the Jaeger model has been used $[4,7]$. Grinding process has been performed using super-hard grinding wheel (cBN 125/100 M75) at the specialized survey station. The temperature measurements have been taken using thermocouples of the K type placed in the blind holes penetrating the surface layer.

\section{Jaeger model basics}

Jaeger model is based on the slightly idealized considerations of the heat transfer mechanism between sliding body and infinite semi-surface [6]. Although idealized, this model proved to be reliable in the strict technical conditions related with the grinding process $[7,8]$ and provide the great help in better understanding of the temperature distribution rules in the surface layer. Here, we have provided some basic ideas concentrated on the application and importance of the heat generation distribution in the contact zone between grinding wheel and machined workpiece (Fig. 1), which is the main feature of the temperature investigations concept presented in the article.

The contact zone length $L_{c}$ as the circular arc-along the grinding wheel:

$$
L_{c}=R \cdot \arcsin \left(\frac{\sqrt{R^{2}-(R-a)^{2}}}{R}\right) \quad a<<R \Rightarrow L_{c} \cong \sqrt{2 R a}
$$

where $R$ is the grinding wheel's outer radius, (m); $a$ is the infeed per one pass, (m).

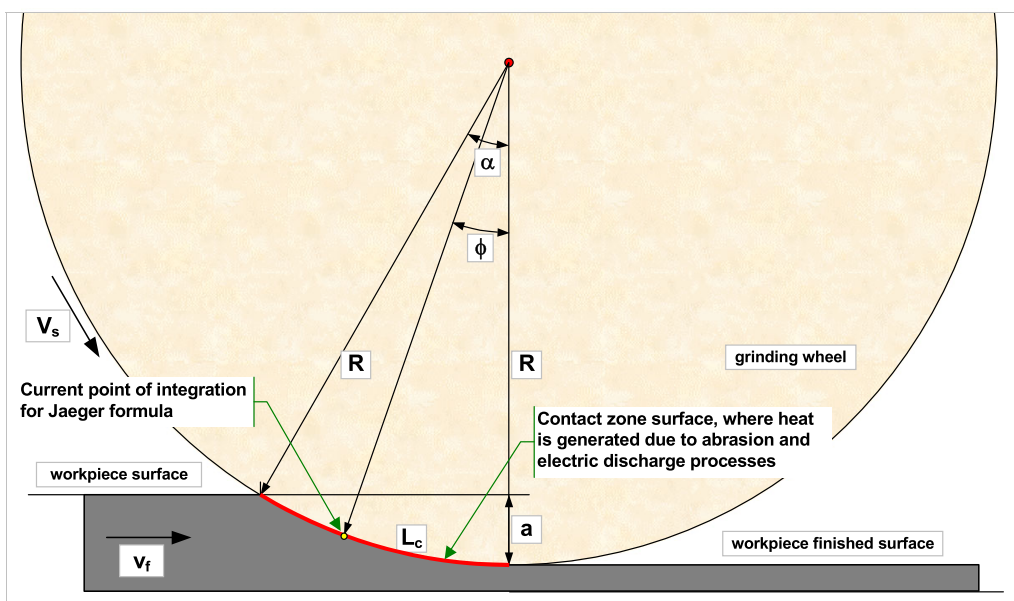

Fig. 1 Sketch of the grinding process for the Jaeger model purpose 


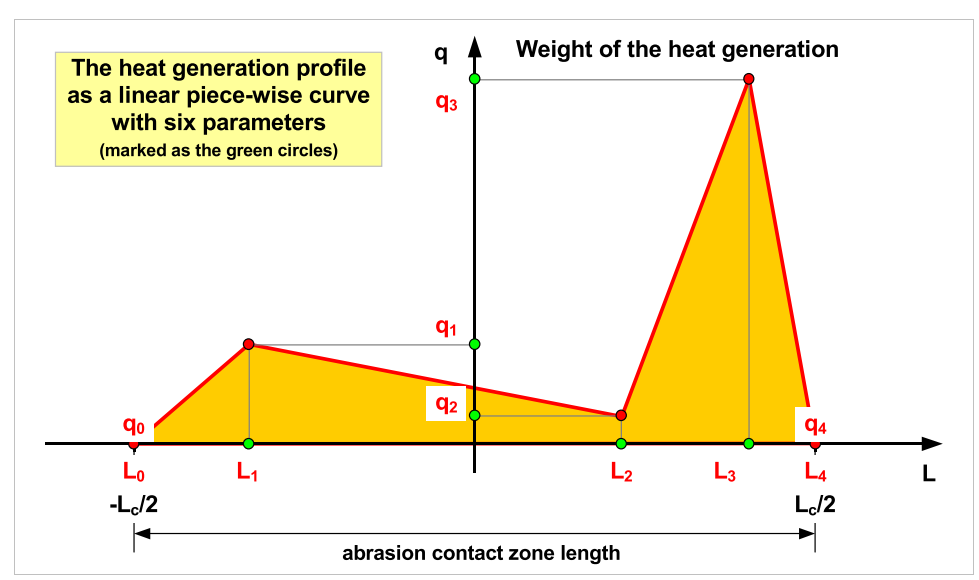

Fig. 2 Proposed heat generation profile as a linear piece-wise curve with six parameters

The temperature distribution function during "shallow grinding" is as follows [6,7]:

$$
\vartheta(x, z)=\frac{1}{\pi} \frac{Q}{k} \int_{-L_{c} / 2}^{L_{c} / 2} \exp \left(-\frac{v_{f}}{2 \alpha}(x-l)\right) \cdot K_{0}\left(\frac{v_{f}}{2 \alpha} \sqrt{(x-l)^{2}+z^{2}}\right) \cdot f(l) \mathrm{d} l
$$

where $x$ is the horizontal coordinate, along the workpiece surface, $(\mathrm{m}) ; z$ is the depth into the workpiece coordinate, (m); $Q$ is the total heat provided through the contact, $(\mathrm{J}) ; k$ is the thermal conduction coefficient of the workpiece material, $[\mathrm{W} /(\mathrm{Km})] ; v_{f}$ is the feed rate of the workpiece-speed of the thermal contact passing over, $(\mathrm{m} / \mathrm{s}) ; \alpha$ is the thermal (heat) diffusivity coefficient of the workpiece material, $\left(\mathrm{m}^{2} / \mathrm{s}\right)$ :

$$
\alpha=\frac{k}{c_{p} \cdot \rho}
$$

where $c_{p}$ is the specific thermal capacity of the workpiece material, $(\mathrm{J} / \mathrm{kg}) ; \rho$ is the specific density of the workpiece material, $\left(\mathrm{kg} / \mathrm{m}^{3}\right) ; K_{0}$ is the modified Bessel function of the second kind, zero-order; $f(\cdot)$ is the spatial heat distribution along the contact $\left(-L_{c} / 2, L_{c} / 2\right)$, a continuous function fulfilling the following physical conditions of heat generation in the contact zone:

$$
\begin{aligned}
& f\left(-L_{c} / 2\right)=f\left(L_{c} / 2\right)=0 \\
& \int_{-L_{c} / 2}^{L_{c} / 2} f(l) \mathrm{d} l=1
\end{aligned}
$$

General rule of the polygon area calculation with given point coordinates is [2]:

$$
A=\frac{1}{2}\left|\sum_{i=0}^{n}\left(L_{i} q_{i+1}-L_{i+1} q_{i}\right)\right|
$$

Applying the formula (5) to the linear piece-wise profile depicted in Fig. 2, taking into account the conditions (4), yields:

$$
A=\frac{1}{2}\left|\left(L_{1} q_{2}-L_{2} q_{1}\right)+\left(L_{2} q_{3}-L_{3} q_{2}\right)-\frac{L_{c}}{2}\left(q_{3}+q_{1}\right)\right|
$$

The above equation sets the basis for normalization of the field $A$ to " 1 " for to apply this profile as a weight function for the heat generation mechanism. All of the numerical calculations have been performed according to [1] using a proprietary software developed by one of the authors. 


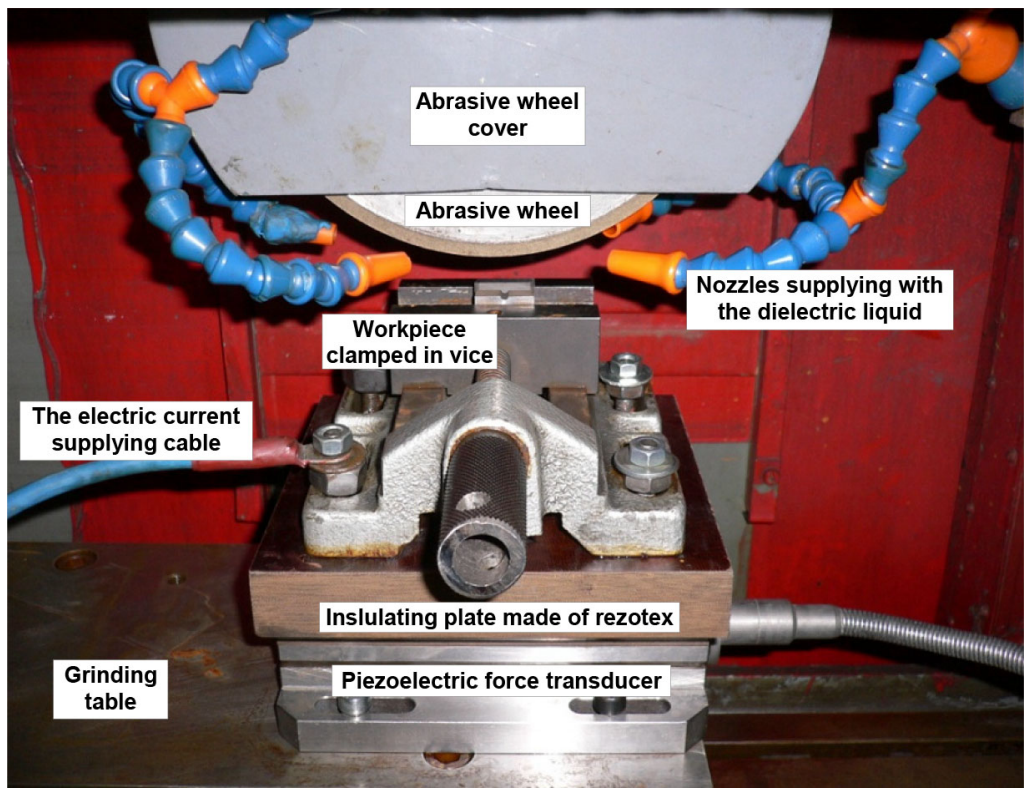

Fig. 3 Grinding machine prepared for the AEDG along with the classical grinding

\section{Survey site, research method and conditions}

The conventional grinding process as well as the AEDG has been conducted at the survey site equipped with surface grinding machine of the ECBT8 type, electrical impulses generator and measurement devices monitoring and controlling grinding parameters. Overview of the grinding zone and basic functional sets of the survey site has been depicted in Fig. 3.

Basic measurements have been taken using two thermocouples of the $\mathrm{K}$ type placed in the blind holes at an equal depth of $500 \mu \mathrm{m}$ from the machined surface, arranged in the square corners as depicted in Fig. 4. The initial outer layer has been subsequently ground with the step of $20 \mu \mathrm{m}$, realizing the idea of measuring temperature at different depths beneath the ground surface. Electrical signals from the thermocouples have been recorded using a computerized measurement system, equipped with necessary hardware and software components. During each passage of grinding, the maximal temperature has been recorded. The pair of thermocouples has been used to assure precise and reliable temperature measurements.

The temperature measurements' methodology determines specific attitude to the mathematical modeling and identification model parameters. We have assumed grinding effective power and shape of the heat distribution curve as the estimated parameters, which have resulted in the very effective fitting of the Jaeger model to our specific process conditions [3,4,7]. From Eq. (2), it could be deduced that heating power $Q$ acts as the scaling factor, shifting the model curve along the temperature axis as depicted in Figs. 5, 6 and 7. The spatial heat distribution along the contact zone-function $f(l)$, acts in our work as the specific model parameter allowing "bending" temperature curve independently of the effective grinding power supplied by abrasion and AEDG processes into the contact zone.

\section{Classical dry grinding}

The technological conditions of dry grinding (without cooling liquid) as well as the physical characteristics of the materials used, are gathered in the Tables 1 and 2. The final results and Jeager model fitting are presented in Fig. 5.

The power dividing ratio, i.e., the part of grinding power assumed to be related with heating process has been set to: $\varepsilon=0.58$, according to work [7]. The effective grinding power: $P_{\mathrm{EFF}}=156.6 \mathrm{~W}$, obtained as the result of model parameters' identification, corresponds well with other works conducted by authors [3-5].

Jaeger model fitting is reasonably well, with the shape of heat distribution curve very close to the "classical" shape reported by other authors $[7,8]$. 


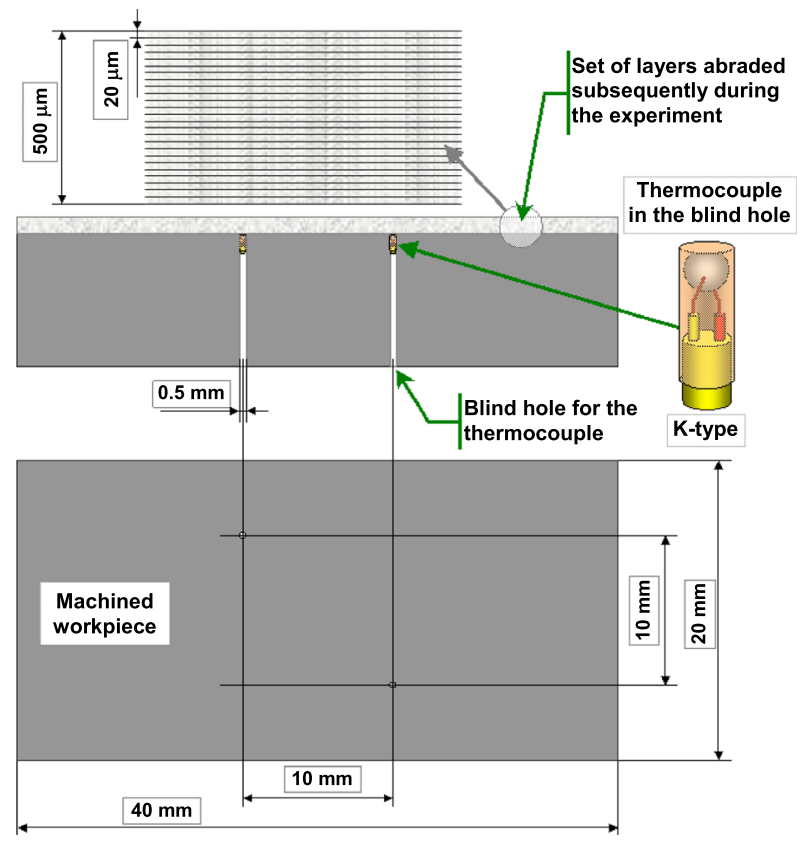

Fig. 4 Temperature measurements' organization with using thermocouples placed in the blind holes under gradually abraded surface of the workpiece

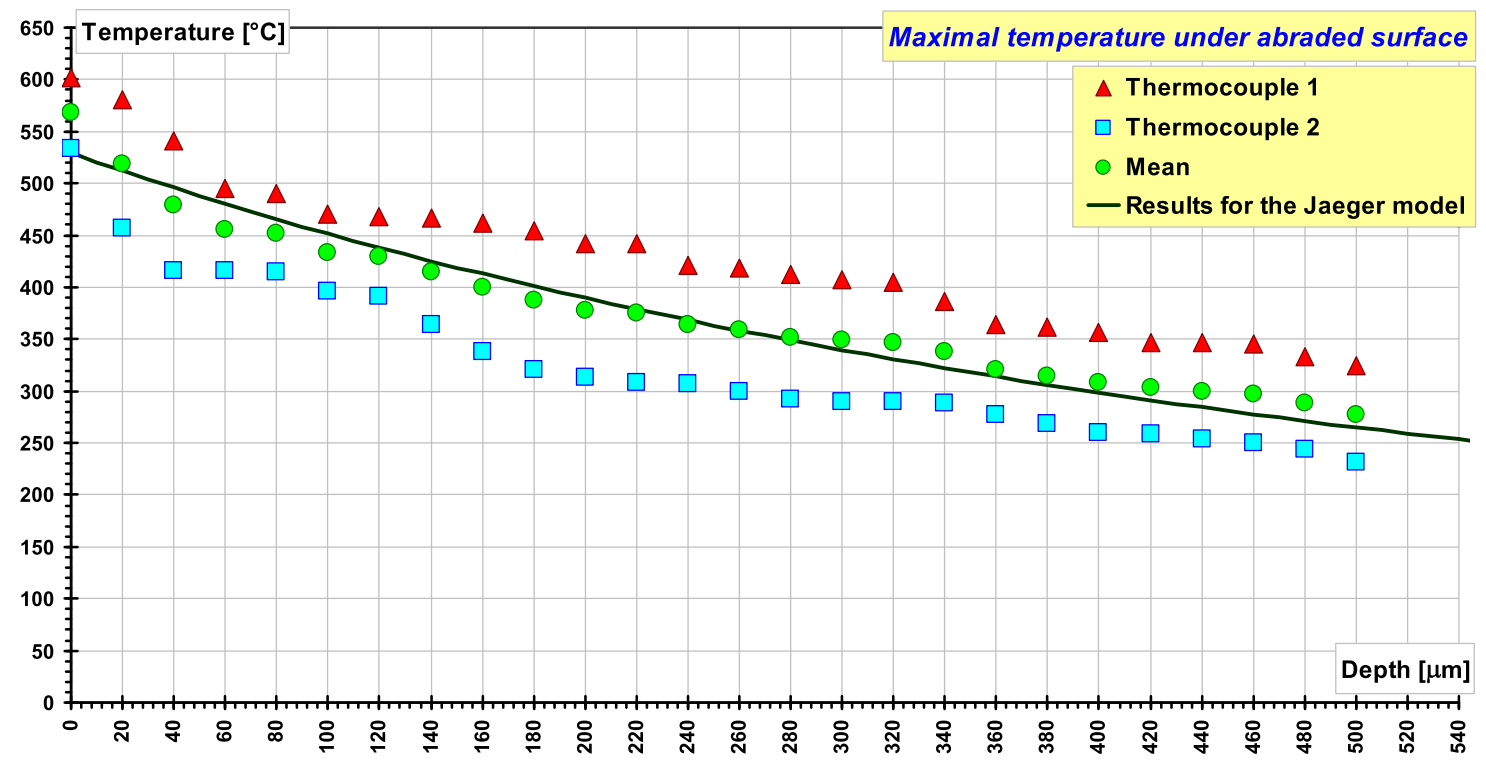

Fig. 5 Experimental results of the temperature measurement under abraded surface for the classical, dry grinding of the Ti6Al4V workpiece with $\mathrm{cBN}$ grinding wheel compared with Jaeger model temperature curve taken for the data exhibited in the Table 2

\section{Classical grinding with cooling}

Tests of titanium alloy grinding using deionized water as coolant have been carried out in the same conditions as dry grinding tests. The technological conditions, as well as the physical characteristics of the materials used, are gathered in Tables 1 and 2. The final results and Jeager model fitting are presented in Fig. 6 (Table 3).

The model fitting (model parameters' identification) procedure resulted in recognizing the effective grinding power: $P_{\mathrm{EFF}}=37.7 \mathrm{~W}$, corresponding well with previous results for classical dry grinding and intensive water cooling using water jets. 


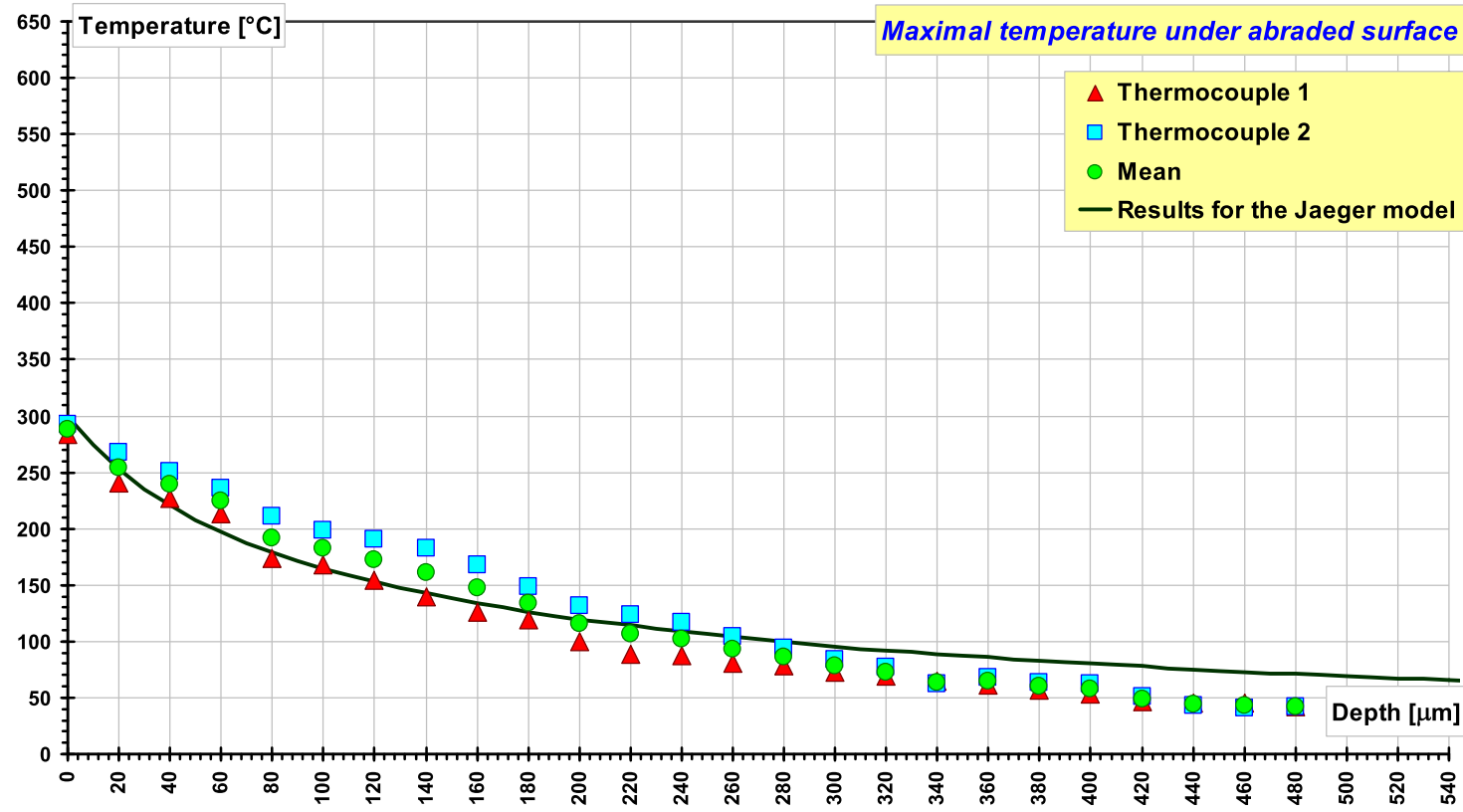

Fig. 6 Experimental results of the temperature measurement under abraded surface for the classical grinding with cooling of the Ti6Al4V workpiece with cBN grinding wheel compared with Jaeger model temperature curve taken for the data exhibited in Table 3

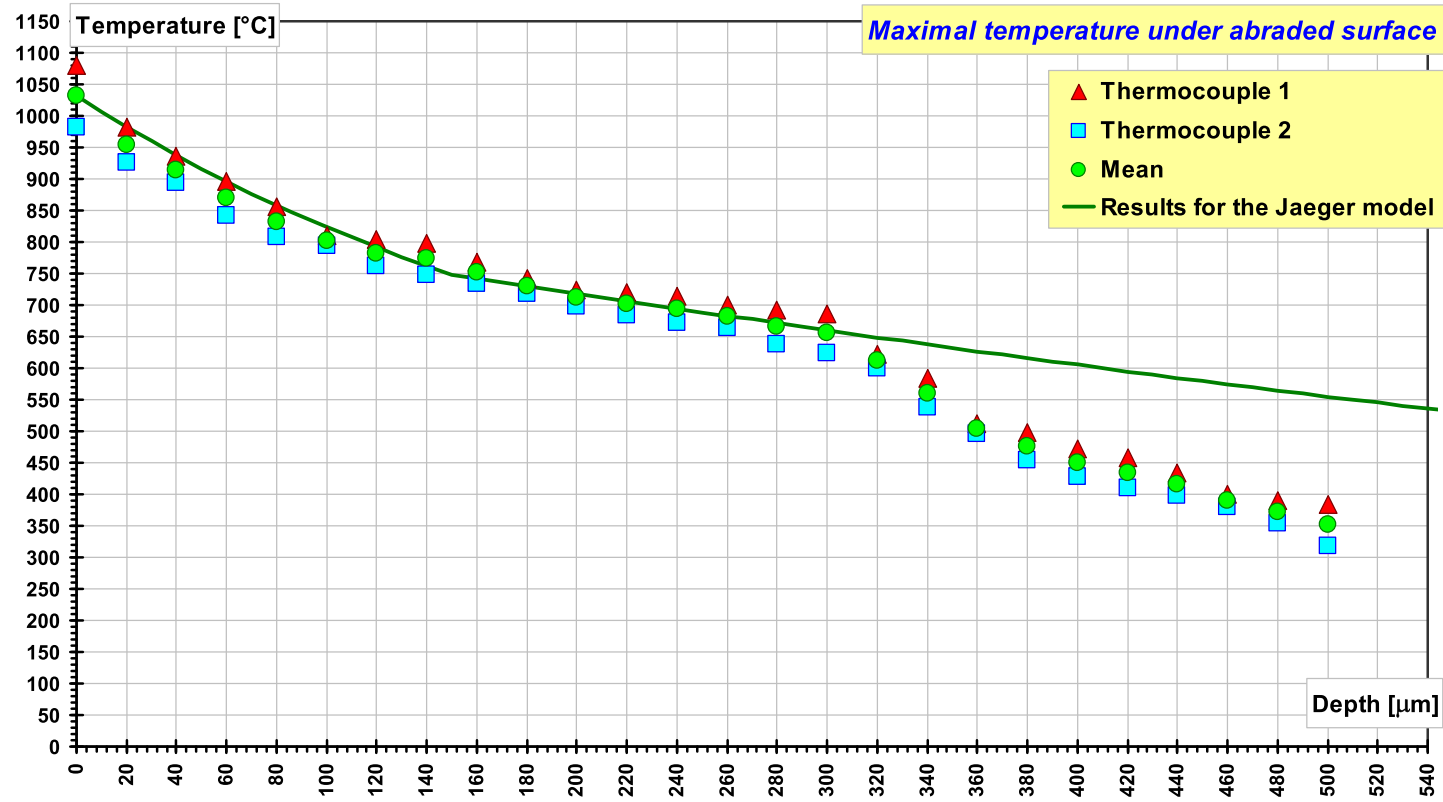

Fig. 7 Experimental results of the temperature measurement under abraded surface for the classical, dry grinding of the Ti6Al4V workpiece with cBN grinding wheel compared with Jaeger model temperature curve taken for the data exhibited in Table 4

Jaeger model fitting is reasonably well, although the heat distribution curve seems to be very specific because of its very high initial peak. This could be explained as the result of very hard material machining, resulting in intensive crushing in the attack sub-zone of the contact and intensive cooling in the rest of the contact zone. 
Table 1 Basic material and mechanical parameters of the classical dry grinding of the Ti6Al4V sample using the cBN grinding wheel

\begin{tabular}{|c|c|c|c|}
\hline \multicolumn{4}{|l|}{ Workpiece } \\
\hline Length & $2 l$ & 40.0 & $\mathrm{~mm}$ \\
\hline Width & $b$ & 20.0 & $\mathrm{~mm}$ \\
\hline Thickness & $d$ & 10.0 & $\mathrm{~mm}$ \\
\hline Volume & $V_{w}$ & $8.00 \mathrm{E}-06$ & $\mathrm{~m}^{3}$ \\
\hline Material type & \multicolumn{3}{|c|}{ Ti6Al4V titanium alloy } \\
\hline Density & $\rho$ & 4420.0 & $\mathrm{~kg} / \mathrm{m}^{3}$ \\
\hline Mass & $m_{\mathrm{W}}$ & 0.0354 & $\mathrm{~kg}$ \\
\hline \multicolumn{4}{|l|}{ Thermal } \\
\hline Specific heat & $c_{\mathrm{p}}$ & 560.0 & $\mathrm{~J} /(\mathrm{kg} \mathrm{K})$ \\
\hline Conductivity & $k^{P}$ & 7.20 & $\mathrm{~W} /(\mathrm{m} \mathrm{K})$ \\
\hline Diffusifity & $a$ & $2.91 \mathrm{E}-06$ & $\mathrm{~m}^{2} / \mathrm{s}$ \\
\hline \multicolumn{4}{|l|}{ Electrical } \\
\hline Resistivity & $\sigma$ & $1.740 \mathrm{E}-04$ & Ohm m \\
\hline \multicolumn{4}{|l|}{ Grinding wheel } \\
\hline \multicolumn{4}{|l|}{ Radius } \\
\hline Outer & $R$ & 125.0 & $\mathrm{~mm}$ \\
\hline Inner & $r$ & 20.0 & $\mathrm{~mm}$ \\
\hline Diameter & $D$ & 250.0 & $\mathrm{~mm}$ \\
\hline Width & $B$ & 30.0 & $\mathrm{~mm}$ \\
\hline Concavity coefficient & & 0.950 & - \\
\hline Volume & $\mathrm{V}_{\mathrm{G}}$ & 0.001363 & $\mathrm{~m}^{3}$ \\
\hline Material type & \multicolumn{3}{|c|}{ CBN 125/100 M75 } \\
\hline
\end{tabular}

Table 2 Summary of data for the Jaeger model calculations for dry grinding

\begin{tabular}{lcc}
\hline Data for the Jaeger model & 32.1 & $\mathrm{~m} / \mathrm{s}$ \\
$V_{\mathrm{S}}$ & 0.50 & $\mathrm{~m} / \mathrm{min}$ \\
$V_{\mathrm{f}}$ & 20.00 & $\mu \mathrm{m}$ \\
$\mathrm{a}$ & 2.236 & $\mathrm{~mm}$ \\
$l_{\mathrm{c}}$ & 270.0 & $\mathrm{~W}$ \\
$P_{\text {GRIND }}$ & 0.0 & $\mathrm{~W}$ \\
$P_{\text {AEDG }}$ & 270.0 & $\mathrm{~W}$ \\
$P_{\text {TOTAL }}$ & 0.5800 & - \\
$\varepsilon$ & 156.6 & $\mathrm{~W}$ \\
$P_{\text {EFF }}$ & $\mathrm{mm}$ & $(-)$ \\
\hline $\mathrm{m}$ & & \\
\hline Heatinq profile & -0.00112 & 0.00000 \\
-1.12 & -0.00105 & 0.15000 \\
-1.05 & -0.00025 & 0.15000 \\
-0.25 & 0.00105 & 2.94363 \\
1.05 & 0.00112 & 0.00000 \\
1.12 & &
\end{tabular}

\section{Elecrodischarge grinding (AEDG)}

The basic technological conditions, as well as the physical characteristics of the materials used, are gathered in Tables 1 and 4. The final results and Jeager model fitting are presented in Fig. 7.

These exemplary results for AEDG grinding using water as dielectrical liquid-as in the previous example of classical grinding with cooling, have been obtained at the following electric parameters: $U=150 \mathrm{~V}$, $I=12 \mathrm{~A}$. One can observe a substantial growth of the heating power due to the sparks' energy provided additionally into the abrasion area. Assuming that cooling efficiency is as previously, the stated power growth is: $P_{\mathrm{AEDG}} \approx 545 \mathrm{~W}$ which correspond well with supplied electric power: $P_{\mathrm{SUPP}}=1800 \mathrm{~W}$, giving the duty cycle: $\delta \approx 30 \%$.

Using $f(l)$ function of the (6) type as the shape-controlling parameters, good fitting has been achieved only to the threshold at the level of $320 \mu \mathrm{m}$. This could be caused by additional physical mechanism of heat transfer into solid which is not taken into account in the Jaeger model assumptions. The lack of perfect fitting in this case, as well as the very specific shape of the temperature distribution in the outer layer, may suggest also the 
Table 3 Summary of data for the Jaeger model calculations for grinding with cooling

\begin{tabular}{lll}
\hline Data for the Jaeger model & & \\
$V_{\mathrm{S}}$ & 32.1 & $\mathrm{~m} / \mathrm{s}$ \\
$V_{\mathrm{f}}$ & 0.50 & $\mathrm{~m} / \mathrm{min}$ \\
$\mathrm{a}$ & 20.00 & $\mu \mathrm{m}$ \\
$l_{\mathrm{c}}$ & 2.236 & $\mathrm{~mm}$ \\
$P_{\text {GRIND }}$ & 65.0 & $\mathrm{~W}$ \\
$P_{\text {AEDG }}$ & 0.0 & $\mathrm{~W}$ \\
$P_{\text {TOTAL }}$ & 65.0 & $\mathrm{~W}$ \\
$\varepsilon$ & 0.5800 & - \\
$P_{\text {EFF }}$ & 37.7 & $\mathrm{~W}$ \\
\hline $\mathrm{m}$ & $\mathrm{mm}$ & $(-)$ \\
\hline Heating profile & & \\
-1.12 & -0.00112 & 0.00000 \\
-1.05 & -0.00105 & 0.10000 \\
0.95 & 0.00095 & 0.10000 \\
1.05 & 0.00105 & 24.13000 \\
1.12 & 0.00112 & 0.00000 \\
\hline
\end{tabular}

Table 4 Summary of data for the Jaeger model calculations for grinding with cooling

\begin{tabular}{lll}
\hline Data for the Jaeger model & & \\
$V_{\mathrm{S}}$ & 32.1 & $\mathrm{~m} / \mathrm{s}$ \\
$V_{\mathrm{f}}$ & 0.50 & $\mathrm{~m} / \mathrm{min}$ \\
$a$ & 20.00 & $\mu \mathrm{m}$ \\
$l_{\mathrm{c}}$ & 2.236 & $\mathrm{~mm}$ \\
$P_{\text {GRIND }}$ & 65.0 & $\mathrm{~W}$ \\
$P_{\mathrm{AEDG}}$ & 543.6 & $\mathrm{~W}$ \\
$P_{\text {TOTAL }}$ & 608.6 & $\mathrm{~W}$ \\
$\varepsilon$ & 0.5800 & - \\
$P_{\mathrm{EFF}}$ & 353.0 & $\mathrm{~W}$ \\
\hline $\mathrm{m}$ & $\mathrm{mm}$ & $(-)$ \\
\hline Heating profile & & \\
-1.12 & -0.00112 & 0.00000 \\
-1.05 & -0.00105 & 0.60000 \\
0.50 & 0.00050 & 0.60000 \\
1.05 & 0.00105 & 3.63000 \\
1.12 & 0.00112 & 0.00000 \\
\hline
\end{tabular}

need of even more flexible modeling of the contact zone heat distribution curve. This could be accomplished with further enhancing of the piece-wise "discrete" model or even changing to the analytical model employing some specific curves with proper degrees of freedom.

\section{Conclusions}

Thorough examinations of the outer layer temperature distribution during classical grinding as well as during AEDG process have brought a lot of useful practical information necessary for effective design of the grinding technological process of the hardly machinable materials. This assures the authors in continuing this way of surveying such a difficult technological problem as outer layer temperature during grinding process.

Obtained results, very promising although introductory, point to the further theoretical investigations focused on the two main directions: experimental verification of the effective heating power value $Q$, and introducing into classical Jaeger model different functions $f(l)$ modeling of the heating power distribution in the contact zone. This should lead to improvement of the mathematical model accuracy and reliability, leading in turn to designing precise grinding technological processes facilitating machining of the hardly machinable materials.

Another valuable result, to some degree additional in our work, has been achieved: Fitting the shape of the heat distribution curve in the contact zone one provide us with powerful experimental tool of researching it, complementary to the direct methods, very complicated in applying them [8]. 
Open Access This article is distributed under the terms of the Creative Commons Attribution 4.0 International License (http:// creativecommons.org/licenses/by/4.0/), which permits unrestricted use, distribution, and reproduction in any medium, provided you give appropriate credit to the original author(s) and the source, provide a link to the Creative Commons license, and indicate if changes were made.

\section{References}

1. Abramowitz, M., Stegun, I.: Handbook of Mathematical Functions With Formulas, Graphs, and Mathematical Tables. National Bureau of Standards, Applied Mathematics Series-55, 10th edn, NIST Publisher, Gaithersburg (1972)

2. Borsuk, K.: Multidimensional Analytical Geometry. PWN, Warsaw (1969)

3. Gołąbczak, A., Kozak, J.: Studies of electrodischarge and electrochemical systems for dressing of metal bond of grinding wheels. J. Eng. Manuf. 220(part B), 413-420 (2006)

4. Golabczak, A., Golabczak, M., Konstantynowicz, A., Swiecik, R., Galant, M.: Modeling and experimental investigations of the surface layer temperature of titanium alloys during AEDG processing. Defect Diffus. Forum 365, 63-70 (2015)

5. Golabczak, A., Święcik, R. (2010) Elecro-discharge grinding: energy consumption and internal in the surface layer. In: Proceedings of the 16th International Symposium on Electromachining, pp. 517-523. Schanghai, China (2010)

6. Jaeger, J.C.: Moving sources of heat and the temperature at sliding contacts. Proc. R. Soc. N.S.W. 76, 203-224 (1942)

7. Kohli, S., Guo, C., Malkin, S.: Energy partition to the workpiece for grinding with aluminum oxide and CBN abrasive wheels. Trans. ASME 117, 160-168 (1995)

8. Srinivasaraghavan M (2009) Experimental and theoretical investigation of force distribution in the grinding contact zone. Master's Thesis, McGill University, Montreal 